\title{
Impaired Endothelial Function in Coronary Heart Disease Patients With Depressive Symptomatology
}

\author{
Andrew Sherwood, PHD, ${ }^{*}$ Alan L. Hinderliter, MD, $†$ Lana L. Watkins, PHD, ${ }^{*}$ Robert A. Waugh, MD,* \\ James A. Blumenthal, PHD*
}

Durham and Chapel Hill, North Carolina

\begin{abstract}
OBJECTIVES The purpose of this study was to assess whether depressive symptomatology was associated with vascular endothelial dysfunction in patients with coronary heart disease (CHD).

BACKGROUND In patients with CHD, the presence of depression is associated with a two to four times increased risk of mortality, but the disease pathways involved are uncertain. Endothelial dysfunction is an established risk factor for cardiovascular events in patients with CHD.

METHODS Flow-mediated dilation (FMD) of the brachial artery, a measure of endothelial function, was assessed in 143 patients ( 99 men, 44 women), ages 40 to 84 years (mean age, $63 \pm 10$ years), with documented CHD.

RESULTS Patients with significant depressive symptomatology, as indicated by a Beck Depression Inventory (BDI) score $\geq 10(\mathrm{n}=47)$ showed attenuated FMD $(\mathrm{p}=0.001)$ compared with patients that were not depressed (BDI $<10 ; n=96)$. The use of antidepressant medication was associated with improved FMD $(p<0.05)$.

CONCLUSIONS The increased risk of cardiovascular events in CHD patients with elevated symptoms of depression may be mediated, in part, by endothelial dysfunction. (J Am Coll Cardiol 2005; 46:656-9) (C) 2005 by the American College of Cardiology Foundation
\end{abstract}

Depression is relatively common in patients with cardiovascular disease $(1,2)$. In patients with coronary heart disease (CHD), depression is associated with a two to four times increased risk of cardiac mortality compared with patients with CHD who are not depressed $(3,4)$. The physiologic mechanisms relating depression to cardiovascular risk are not known, but there is evidence that depression is associated with dysregulation of the autonomic nervous system and hypothalamic-pituitary-adrenal axis, blood hypercoagulability, and increased inflammation $(2,5)$.

Vascular endothelial dysfunction is another pathway through which depression may increase cardiovascular risk. Endothelial dysfunction features prominently in the development, progression, and clinical manifestations of atherosclerosis $(6,7)$. Flow-mediated dilation (FMD) of the brachial artery is a noninvasive index of endothelial function that is related to coronary vessel dysfunction (8) and is associated with a wide range of cardiovascular risk factors (9). Prospective studies of patients with cardiovascular disease indicate that endothelial dysfunction is an independent predictor of cardiovascular events (10).

Two recent studies have reported that FMD was significantly lower in patients with major depressive disorder compared with healthy control subjects $(11,12)$. Another recent study observed depressive symptoms to be inversely related to FMD in healthy postmenopausal women (13). However, no studies to date have evaluated the relationship

From the *Duke University Medical Center, Durham, North Carolina; and †University of North Carolina at Chapel Hill, Chapel Hill, North Carolina. This research was supported by Grant HL 59672 from the National Institutes of Health, Bethesda, Maryland, and grant M01-RR-30 from the General Clinical Research Center program, National Center for Research Resources, National Institutes of Health.

Manuscript received January 4, 2005; revised manuscript received April 4, 2005, accepted May 27, 2005. of depression with FMD in patients with documented CHD.

\section{METHODS}

Study subjects. One hundred forty-three patients ( 99 men, 44 women), age 40 to 84 years (mean age, $63 \pm 10$ years) with documented CHD (by previous myocardial infarction $[\mathrm{MI}]$, coronary artery bypass graft surgery, coronary angioplasty, or $\geq 75 \%$ stenosis in at least one major coronary artery) and recent ( $\leq 1$ year) evidence of exercise-induced myocardial ischemia participated in this study. Patients with cardiomyopathy, valvular heart disease, congestive heart failure, severe cardiac arrhythmias, left bundle branch block, Wolff-Parkinson-White syndrome, a resting blood pressure $>200 / 120 \mathrm{~mm} \mathrm{Hg}$, ejection fraction $<30 \%$, or left main coronary artery stenosis $\geq 50 \%$ were excluded. All study subjects indicated that they were sedentary at the time of enrollment. Because study subjects were scheduled to also undergo stress testing to evaluate myocardial ischemia, anti-ischemic medications (nitrates, beta-blockers, calcium channel blockers) were tapered and discontinued, in subjects in whom this could be achieved safely, at least $48 \mathrm{~h}$ before the present study assessments. All other medications were continued as normal, with the exception of aspirin, which was postponed on the day of testing until completion of the FMD assessment. This study was approved by the Institutional Review Board at Duke University Medical Center, and informed consent was obtained from all participants before their participation.

Assessment of vascular endothelial function. Brachial artery FMD was assessed in the morning, after overnight fasting. Longitudinal $\mathrm{B}$-mode ultrasound images of the brachial artery, 4 to $6 \mathrm{~cm}$ proximal to the antecubital crease, 


$$
\begin{aligned}
& \text { Abbreviations and Acronyms } \\
& \begin{aligned}
\text { ANCOVA } & =\text { analysis of covariance } \\
\text { BDI } & =\text { Beck Depression Inventory } \\
\text { CHD } & =\text { coronary heart disease } \\
\text { FMD } & =\text { flow-mediated dilation } \\
\text { GTN } & =\text { glyceryl trinitrate } \\
\text { GTN-D } & =\text { glyceryl trinitrate dilation } \\
\text { LDL } & =\text { low-density lipoprotein } \\
\text { MI } & =\text { myocardial infarction }
\end{aligned}
\end{aligned}
$$

were obtained using an Acuson (Mountain View, California) Aspen ultrasound platform with an $11-\mathrm{MHz}$ linear array transducer. Images were obtained under the following conditions: 1) after 10 min of supine relaxation; 2) during reactive hyperemia, induced after inflation for $5 \mathrm{~min}$ to suprasystolic pressure $(\sim 200 \mathrm{~mm} \mathrm{Hg})$ of an occlusion cuff placed around the forearm; 3 ) after a second $10-\min$ period of supine relaxation; and 4) after the administration of 400 $\mu \mathrm{g}$ sublingual glyceryl trinitrate (GTN) spray. End-diastolic images were stored to magnetic-optical disk, and arterial diameters were measured as the distance between the arterial wall intima-media interfaces using PC-based software (Brachial Analyzer Version 4.0, Medical Imaging Applications LLC, Iowa City, Iowa). The FMD was defined as the maximum percent change in arterial diameter from 10 to $120 \mathrm{~s}$ post-deflation of the occlusion cuff.
Glyceryl trinitrate dilation (GTN-D) was defined as peak percent change in arterial diameter 3 to $5 \mathrm{~min}$ after the administration of GTN. Assessments of FMD and GTN-D were performed by personnel who were blinded to depression status.

Assessment of depression symptoms. The Beck Depression Inventory (BDI) is a 21-item self-reported measure of depressive symptomatology (14). A score of 10 or greater is considered an indication of clinically significant depressive symptoms $(15,16)$ and is associated with poorer prognosis in patients with CHD (17). Although it is not a basis for the clinical diagnosis of depression, in the current report a BDI $\geq 10$ was used to categorize subjects as "depressed."

Statistical analyses. Characteristics of depressed and nondepressed subjects were compared using the Student $t$ test and chi-square test. Analysis of covariance (ANCOVA) was used to evaluate the effects of depression on FMD and GTN-D. A probability value of $p<0.05$ was used to

\begin{tabular}{|c|c|c|c|}
\hline & $\begin{array}{c}\text { Depressed BDI } \geq 10 \\
(n=47)\end{array}$ & $\begin{array}{c}\text { Non-Depressed BDI }<10 \\
(n=96)\end{array}$ & p Value \\
\hline Gender, $\%$ female & 55 & 24 & 0.013 \\
\hline Age, yrs & $60 \pm 10$ & $64 \pm 10$ & 0.012 \\
\hline Weight, $\mathrm{kg}$ & $85.8 \pm 19.2$ & $88.4 \pm 17.6$ & 0.422 \\
\hline Height, m & $1.69 \pm 0.11$ & $1.73 \pm 0.90$ & 0.027 \\
\hline BMI, $\mathrm{kg} / \mathrm{m}^{2}$ & $29.9 \pm 5.3$ & $29.4 \pm 4.8$ & 0.595 \\
\hline $\mathrm{SBP}, \mathrm{mm} \mathrm{Hg}$ & $136 \pm 22$ & $138 \pm 18$ & 0.455 \\
\hline $\mathrm{DBP}, \mathrm{mm} \mathrm{Hg}$ & $76 \pm 9$ & $77 \pm 8$ & 0.540 \\
\hline Hypertension, \% & 53 & 55 & 0.820 \\
\hline Ejection fraction, $\%$ & $58 \pm 11$ & $58 \pm 10$ & 0.832 \\
\hline HDL, mg/dl & $47.1 \pm 10.4$ & $46.4 \pm 12.6$ & 0.149 \\
\hline $\mathrm{LDL}, \mathrm{mg} / \mathrm{dl}$ & $113.6 \pm 34.4$ & $103.1 \pm 26.9$ & 0.045 \\
\hline Triglycerides, $\mathrm{mg} / \mathrm{dl}$ & $163.7 \pm 78.7$ & $152.3 \pm 71.9$ & 0.460 \\
\hline History of hypercholesterolemia, \% & 87 & 90 & 0.676 \\
\hline Smokers, \% & 17 & 9 & 0.185 \\
\hline Family history of CHD, \% & 70 & 64 & 0.430 \\
\hline BDI score & $16 \pm 5$ & $4 \pm 3$ & $<0.0001$ \\
\hline Resting brachial artery diameter, $\mathrm{mm}$ & $4.36 \pm 0.74$ & $4.49 \pm 0.91$ & 0.353 \\
\hline Beta-blockers, $\%$ & 19 & 17 & 0.714 \\
\hline Calcium channel blockers, $\%$ & 8 & 5 & 0.445 \\
\hline Nitrates, \% & 10 & 6 & 0.355 \\
\hline Statins, $\%$ & 68 & 72 & 0.640 \\
\hline ACE inhibitors, $\%$ & 36 & 43 & 0.387 \\
\hline Diuretics, \% & 32 & 20 & 0.109 \\
\hline Diabetes, $\%$ & 19 & 14 & 0.383 \\
\hline Antidepressants, \% & 45 & 8 & $<0.0001$ \\
\hline
\end{tabular}
denote statistical significance.

\section{RESULTS}

Clinical characteristics. Forty-seven patients (33\%) met the BDI criteria $(\geq 10)$ for significant depressive symptomatology, and 96 subjects were not depressed (BDI $<10$ ). Clinical characteristics of the study sample are summarized in Table 1. The depressed group was younger $(p=0.012)$,

Table 1. Study Sample Characteristics 


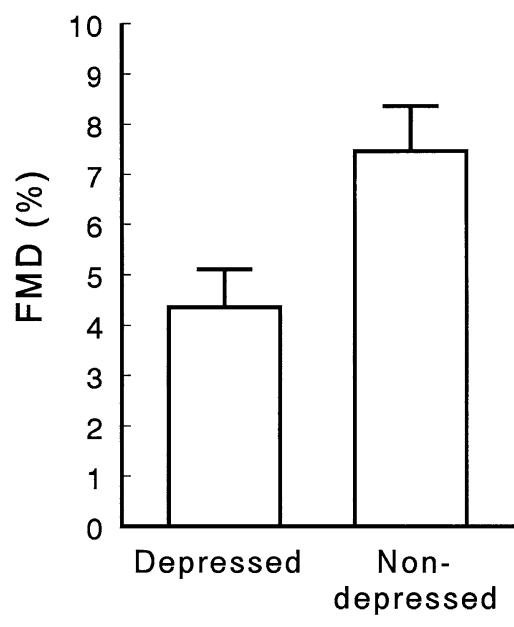

Figure 1. Flow-mediated dilation (FMD) in 47 depressed (Beck Depression Inventory $\geq 10$ ) and 96 nondepressed (Beck Depression Inventory $<10)$ patients with coronary heart disease (adjusted means \pm SEM).

comprised a greater proportion of women $(p=0.013)$, and had higher low-density lipoprotein (LDL) cholesterol levels $(p=0.045)$ than nondepressed subjects. Twentyeight subjects were taking antidepressant medication, with most $(n=21)$ taking a selective serotonin reuptake inhibitor.

Endothelial function. The effect of depression on FMD was evaluated by ANCOVA, with age, gender, baseline arterial diameter, and cardiovascular and antidepressant medications included as covariates. As shown in Figure 1, FMD was significantly impaired in depressed compared with nondepressed subjects (adjusted means \pm SE: $4.36 \pm$ $0.75 \%$ vs. $7.46 \pm 0.89 \%, p=0.001)$. Because patients in the depressed group exhibited higher LDL cholesterol levels (Table 1), we also considered LDL as a covariate. However, LDL was unrelated to FMD ( $p=0.318)$ in our sample and had negligible impact on the relationship between depression and FMD ( $p=0.001$ vs. $p=0.004)$. Antidepressant medication use was associated with improved FMD compared with subjects not taking antidepressants (adjusted means \pm SE: $6.90 \pm 0.9 \%$ vs. $4.93 \pm 0.7 \%, p=0.038$ ). There was no significant interaction between depression status and antidepressant medication use $(p=0.14)$. Age and baseline arterial diameter also were significant determinants of the FMD response $(p=0.001$ and $p=0.0005$, respectively) in the ANCOVA model.

Glyceryl trinitrate dilation was evaluated using the same aforementioned ANCOVA model described for FMD. Neither depression nor antidepressant medication use was a significant determinant of GTN-D (depressed vs. nondepressed GTN-D $=12.2 \pm 1.3 \%$ vs. $14.3 \pm 1.5 \%, \mathrm{p}=$ 0.143 ; medication vs. no medication GTN-D $=12.1 \pm$ $1.5 \%$ vs. $14.4 \pm 1.2 \%, \mathrm{p}=0.187)$. Age and baseline arterial diameter were the only significant factors related to the GTN response $(\mathrm{p}=0.0008$ and $\mathrm{p}<0.0001$, respectively).

\section{DISCUSSION}

The present study found that CHD patients with elevated symptoms of depression exhibited impaired endothelial function compared with nondepressed CHD patients. To our knowledge, this evidence of an attenuated FMD response associated with depression is the first documentation of the phenomenon in a CHD population and extends previous observations that depression is associated with endothelial dysfunction in otherwise-healthy individuals (11-13). The observed association of elevated symptoms of depression with attenuated FMD, but not with GTN-D, suggests that vascular functional impairment was not generalized but specific to the endothelium (9).

Recent evidence suggests that impaired endothelial function may be an independent predictor of cardiovascular events. Neunteufl et al. (18) studied 73 patients with angina undergoing cardiac catheterization and found FMD to be an independent predictor of death and MI during a five-year follow-up period. Heitzer et al. (19) found that endothelial dysfunction predicted cardiovascular events (death, MI, stroke, coronary revascularization) during a 4.5-year mean follow-up period in 281 patients with CHD. Similar prospective observations have been made in patients with CHD (20), untreated hypertension (21), and documented peripheral vascular disease (22). This evidence has led to the suggestion that endothelial dysfunction provides a "barometer" of cardiovascular risk (23). Our present observations raise the possibility that depression may impart an increased risk of cardiovascular events in patients with CHD because of its association with endothelial dysfunction. However, the cause-effect nature of the relationship between depression and endothelial dysfunction cannot be deduced from these cross-sectional data. Also, it is unclear whether endothelial dysfunction is a direct pathway relating depression to cardiovascular risk or simply represents a marker of other cardiovascular risk factors related to endothelial dysfunction (9).

Currently, there is no evidence to indicate that successful treatment of depression may be accompanied by improved endothelial function or the amelioration of cardiovascular risk associated with depression. Results from the Enhancing Recovery in Coronary Heart Disease Patients (ENRICHD) trial (24) revealed that despite modest improvements in depressive symptoms in patients treated with cognitive behavior therapy, there was no effect on subsequent risk of fatal and recurrent coronary events. However, patients who received antidepressant medication had better survival compared with patients not receiving medication (24). In the Sertraline Antidepressant Heart Attack Randomized Trial (SADHART) (25), after 24 weeks of treatment with sertraline or placebo, there was no difference in reduction of depressive symptoms as measured by the Hamilton Rating Scale in the main analysis of 369 CHD patients with major depressive disorder; however, the incidence of severe cardiac events was only $14.5 \%$ in the sertraline group compared with $22.4 \%$ in the placebo group. Our present finding that 
antidepressant medication use was associated with improved FMD raises the possibility that antidepressants may lower cardiovascular risk in part through favorable alterations in vascular endothelial function. Future studies examining the impact of treatments for depression on endothelial function and cardiovascular risk are warranted.

Reprint requests and correspondence: Dr. Andrew Sherwood, Box 3119, Duke University Medical Center, Durham, North Carolina 27710. E-mail: sherw002@mc.duke.edu.

\section{REFERENCES}

1. Davidson KW, Rieckmann N, Lesperance F. Psychological theories of depression: potential application for the prevention of acute coronary syndrome recurrence. Psychosom Med 2004;66:165-73.

2. Lett HS, Blumenthal JA, Babyak MA, et al. Depression as a risk factor for coronary artery disease: evidence, mechanisms, and treatment. Psychosom Med 2004;66:305-15.

3. Frasure-Smith N, Lesperance F, Gravel G, et al. Social support, depression, and mortality during the first year after myocardial infarction. Circulation 2000;101:1919-24.

4. Barefoot JC, Helms MJ, Mark DB, et al. Depression and long-term mortality risk in patients with coronary artery disease. Am J Cardiol 1996;78:613-7.

5. Joynt KE, Whellan DJ, O'Connor CM. Depression and cardiovascular disease: mechanisms of interaction. Biol Psychiatry 2003;54:248-61.

6. Bonetti PO, Lerman LO, Lerman A. Endothelial dysfunction: a marker of atherosclerotic risk (review). Arterioscler Thromb Vasc Biol 2003;23:168-75.

7. Brevetti G, Silvestro A, Schiano V, Chiariello M. Endothelial dysfunction and cardiovascular risk prediction in peripheral arterial disease: additive value of flow-mediated dilation to ankle-brachial pressure index. Circulation 2003;108:2093-8.

8. Kaku B, Mizuno S, Ohsato K, et al. The correlation between coronary stenosis index and flow-mediated dilation of the brachial artery. Jpn Circ J 1998;62:425-30.

9. Celermajer DS, Sorensen KE, Gooch VM, et al. Non-invasive detection of endothelial dysfunction in children and adults at risk of atherosclerosis. Lancet 1992;340:1111-5.

10. Mancini GB. Vascular structure versus function: is endothelial dysfunction of independent prognostic importance or not? J Am Coll Cardiol 2004;43:624-8.
11. Rajagopalan S, Brook R, Rubenfire M, Pitt E, Young E, Pitt B. Abnormal brachial artery flow-mediated vasodilation in young adults with major depression. Am J Cardiol 2001;88:196-8.

12. Broadley AJ, Korszun A, Jones CJ, Frenneaux MP. Arterial endothelial function is impaired in treated depression. Heart 2002;88:521-3.

13. Harris KF, Matthews KA, Sutton-Tyrrell K, Kuller LH. Associations between psychological traits and endothelial function in postmenopausal women. Psychosom Med 2003;65:402-9.

14. Beck AT, Beamesderfer A. Assessment of depression: the depression inventory. Mod Probl Pharmacopsychiatry 1974;7:151-69.

15. Beck AT, Steer RA. Beck Depression Inventory Manual. San Antonio, TX: The Psychological Corporation, Harcourt-Brace-Jovanovich, 1987:1.

16. Carney RM, Rich MW, Tevelde A, Saini J, Clark K, Jaffe AS. Major depressive disorder in coronary artery disease. Am J Cardiol 1987;60: 1273-5.

17. Frasure-Smith N, Lesperance F, Talajic M. Depression and 18-month prognosis after myocardial infarction. Circulation 1995;91:999-1005.

18. Neunteufl T, Heher S, Katzenschlager R, et al. Late prognostic value of flow-mediated dilation in the brachial artery of patients with chest pain. Am J Cardiol 2000;86:207-10.

19. Heitzer T, Schlinzig T, Krohn K, Meinertz T, Munzel T. Endothelial dysfunction, oxidative stress, and risk of cardiovascular events in patients with coronary artery disease. Circulation 2001;104:2673-8.

20. Chan SY, Mancini GB, Kuramoto L, Schulzer M, Frohlich J, Ignaszewski A. The prognostic importance of endothelial dysfunction and carotid atheroma burden in patients with coronary artery disease. J Am Coll Cardiol 2003;42:1037-43.

21. Perticone F, Ceravolo R, Pujia A, et al. Prognostic significance of endothelial dysfunction in hypertensive patients. Circulation 2001; 104:191-6.

22. Gokce N, Keaney JF Jr., Hunter LM, et al. Predictive value of noninvasively determined endothelial dysfunction for long-term cardiovascular events in patients with peripheral vascular disease. J Am Coll Cardiol 2003;41:1769-75.

23. Vita JA, Keaney JF Jr. Endothelial function: a barometer for cardiovascular risk? Circulation 2002;106:640-2.

24. Berkman LF, Blumenthal J, Burg M, et al. Effects of treating depression and low perceived social support on clinical events after myocardial infarction: the Enhancing Recovery in Coronary Heart Disease Patients (ENRICHD) Randomized Trial. JAMA 2003;289: 3106-16.

25. Glassman AH, O'Connor CM, Califf RM, et al. Sertraline treatment of major depression in patients with acute MI or unstable angina. JAMA 2002;288:701-9. 